\title{
Gallium Ga 68-NOTA-AE105
}

National Cancer Institute

\section{Source}

National Cancer Institute. Gallium Ga 68-NOTA-AE105. NCI Thesaurus. Code C121954.

A radiotracer composed of AE105, an urokinase-type plasminogen activator receptor (UPAR) peptide antagonist, conjug ated with the bifunctional, macrocyclic chelating agent 1,4,7-triazacyclononane-N,N',N"-triacetic acid (NOTA) and labeled with the radionuclide gallium Ga 68, with potential imaging activity using positron emission tomography (PET). Upon administration, the AE105 moiety of gallium Ga 68-NOTA-AE105 targ ets and binds, with high affinity, to UPAR expressed on tumor cells. Upon PET imaging, UPAR-expressing tumor cells can be visualized and the degree of tumor aggressiveness can be assessed. UPAR expression is correlated with increased tumor invasiveness and aggressiveness, as well as a poor prognosis. 